\title{
Brain Metabolism in Rats with Neuropathic Pain Induced by Brachial Plexus Avulsion Injury and Treated via Electroacupuncture
}

This article was published in the following Dove Press journal:

Journal of Pain Research

\author{
Bei-Bei Huol,* \\ Mou-Xiong Zheng ${ }^{2, *}$ \\ Xu-Yun Hua ${ }^{2} *$ \\ Jun Shen ${ }^{3}$ \\ Jia-Jia $\mathrm{Wu}^{4}$ \\ Jian-Guang Xu'
}

'School of Rehabilitation Science, Shanghai University of Traditional Chinese Medicine, Shanghai, People's Republic of China; ${ }^{2}$ Department of

Traumatology and Orthopedics, Yueyang Hospital, Shanghai University of

Traditional Chinese Medicine, Shanghai,

People's Republic of China; ${ }^{3}$ Department of Orthopedic, Guanghua Hospital of Integrative Chinese and Western Medicine, Shanghai University of Traditional Chinese Medicine, Shanghai, People's Republic of China; ${ }^{4}$ Department of Rehabilitation Medicine, Yueyang Hospital, Shanghai University of Traditional Chinese Medicine, Shanghai, People's Republic of China

*These authors contributed equally to this work

\begin{abstract}
Purpose: Brain organisation is involved in the mechanism of neuropathic pain. Acupuncture is a common clinical practise in traditional Chinese medicine for the treatment of chronic pain. This study explored electroacupuncture's effects on brain metabolism following brachial plexus avulsion injury (BPAI)-induced pain.

Methods: A total of 32 female rats were randomised into a normal group, model group, sham electroacupuncture group, and electroacupuncture group. A pain model was included via right BPAI. The electroacupuncture intervention at cervical "Jiaji" points (C5-7) was performed for 11 weeks. The mechanical withdrawal threshold of the non-injured (left) forepaw was measured at the baseline and on days 3, 7, 14, 21, 28, 56, 84, and 112 subsequent to BPAI. Positron emission tomography (PET) was applied to explore metabolic changes on days 28,84 , and 112 .

Results: After electroacupuncture, the mechanical withdrawal threshold of the left forepaws was significantly elevated and the effect persisted until 4 weeks after the intervention ceased $(\mathrm{p}<0.05$ or $\mathrm{p}<0.001)$. In the sensorimotor-related brain regions, standardised uptake values in the bilateral somatosensory and motor cortices were observed in the electroacupuncture group. Metabolism particularly increased in the right somatosensory cortex. Metabolism changes also occurred in the pain-related brain regions and emotion- and cognition-related brain regions.

Conclusion: The present study demonstrated the beneficial effects of electroacupuncture for relieving BPAI-induced neuropathic pain in rats. Electroacupuncture intervention might inhibit maladaptive plasticity in brain areas governing multidimensional functions, especially in sensorimotor- and cognition-related cortices.
\end{abstract}

Keywords: brachial plexus avulsion injury, neuropathic pain, metabolic mechanism, small animal ${ }^{18} \mathrm{~F}$-FDG PET/CT, electroacupuncture

\section{Introduction}

Brachial plexus avulsion injury (BPAI) is a type of devastating damage that causes upper extremity disability. ${ }^{1}$ It not only affects physical and psychological function but also causes neuropathic pain in many patients. Neuropathic pain is a common complication of BPAI, characterised by burning, crushing, and shooting pain or electric shock sensations. ${ }^{2-4}$ Chronic pain, with an incidence of $30-80 \%,{ }^{5}$ seriously affects the patients' quality of life and has been one of the most challenging problems in medicine and biology. ${ }^{6-8}$ Unfortunately, neuropathic pain is usually resistant to medical treatment and has a high recurrence rate even after invasive interventions. $^{9}$
Correspondence: Jian-Guang Xu School of Rehabilitation Science, Shanghai University of Traditional Chinese

Medicine, No. 1200 Cailun Road, Shangha 201203, People's Republic of China

Tel +862 I-5I32209|

Fax +86 2I-5I 322042

Email xjg@shutcm.edu.cn 
Multidimensional aspects may be involved in the mechanism of neuropathic pain. Accumulating evidence indicates that brain plasticity is an important contribution. $^{10,11}$ Large-scale brain organisation may be critical to its development and maintenance. ${ }^{12}$ Alterations of the cortical structures have proved to be related to the regions that correspond to the affected limb. ${ }^{10}$ Neuroplasticity may also include subcortical areas. ${ }^{13}$

Acupuncture is one of the oldest clinical practises in traditional Chinese medicine for the treatment of many symptoms and disorders, such as stroke, Alzheimer's disease, and chronic pain. The pathologies of acupuncture are also related to neural plasticity. ${ }^{14,15}$ In previous studies, Wang et al suggested that electroacupuncture (EA) reduces the effects of electrical activity of pain-related neurons in the hippocampus of rats with neuropathic pain. ${ }^{16}$ Using fMRI, Theysohn et al found that acupuncture could modulate brain activity under pain conditions in the cingulate gyrus, insula, primary somatosensory cortex, and prefrontal areas. ${ }^{17}$ However, how EA affects brain metabolism following BPAI-induced pain is largely unknown.

With rapid progress of neuroimaging techniques, dynamic central mechanisms of nociceptive information processing could be explored under noninvasive conditions. Positron emission tomography (PET) is a useful method for the study of brain function and the early diagnosis of nervous system diseases. ${ }^{18} \mathrm{~F}$-fluorodeoxyglucose $\left({ }^{18} \mathrm{FDG}\right)$, which is an analogue of glucose labelled with the radionuclide ${ }^{18} \mathrm{~F}$, is the most widely used radiopharmaceutical in PET to monitor the brain's glucose metabolic rate. ${ }^{18}$

As it was inapplicable to compare pre- and post-BPAI brain mechanism in human patients, we applied EA in rats with BPAI-induced pain and tested their dynamic brain mechanisms using small animal PET.

\section{Methods}

\section{Animals}

A total of 32 healthy female Sprague-Dawley (SD) rats (weighing 180-200 $\mathrm{g}$ and aged 6-8 weeks) were housed in a laboratory environment maintained at $20-22^{\circ} \mathrm{C}$ with a 12-h light-dark cycle and given sufficient food and water for at least 1 week before any intervention. The rats were obtained from Shanghai Slack Laboratory Animal Limited Liability Company (Shanghai, China).

The rats were randomly divided into four groups (eight rats in each group): a normal group, model group, sham electroacupuncture (sham EA) group, and electroacupuncture (EA) group. The present study focused on the effects of EA on brain metabolism following BPAI-induced neuropathic pain. The feasibility of the BPAI-induced neuropathic pain model was already confirmed in our previous studies, ${ }^{19}$ we did not include a sham surgery group.

The protocols were in accordance with the Guide for the Care and Use of Laboratory Animals published by the US National Institutes of Health and approved by the Animal Ethical Committee of Shanghai University of Traditional Chinese Medicine (Protocol number: SZY20171211001).

\section{BPAI Model}

The rats were anesthetised with sodium pentobarbital through intraperitoneal injection $(40 \mathrm{mg} / \mathrm{kg})$. After the scuff was shaved, each rat was placed in a prone position on a heated clean surgical table. A longitudinal $4 \mathrm{~cm}$ incision was made along the dorsal midline from the occiput to scapula angulus superior. The longissimus capitis muscle, semispinalis muscle of the neck, biventer cervicis, and complex muscle were pulled aside. Then, the muscles on the vertebral plate and spinal process were removed, and hemilaminectomies from $\mathrm{C} 4$ to $\mathrm{T} 1$ were performed to expose the nerve roots from $\mathrm{C} 5$ to $\mathrm{T} 1$. The $\mathrm{C} 5, \mathrm{C} 6, \mathrm{C} 7, \mathrm{C} 8$, and $\mathrm{T} 1$ nerve roots on the right side were identified and avulsed from the spinal cord using a retractor (Figure 1A and B). After applying penicillin powder to the wound, the tissue layers and skin were closed with 4-0 silk sutures. All of the procedures were completed by the same technician using an operating microscope. (magnification $\times 10$ )

\section{Interventions}

The EA intervention was performed at a relatively fixed time on the seventh day after BPAI. During the intervention, the environment was quiet under controlled room temperature $\left(25.0 \pm 1.0^{\circ} \mathrm{C}\right)$. The rats were placed on a custom-made experimental table and disposable sterile stainless-steel needles were inserted on the left cervical side "Jiaji" points EX-C5, EX-C6, and EX-C7 (5 mm lateral to $\mathrm{C} 5-\mathrm{C} 7$ on the left side at a depth of 3-5 mm) according to acupoint atlas for experimental animal rats (Figure 1C). ${ }^{20}$ The needle handles were connected to the output terminal of an electroacupuncture instrument. The EA parameters were set at dense dispersive waves of 2/15 $\mathrm{Hz}$, and the current intensity was adjusted to induce slight muscle twitching. ${ }^{21}$ The EA intervention was performed $30 \mathrm{mins} /$ day, 5 days per week for 11 weeks. All of the rats 


\section{A Normal}
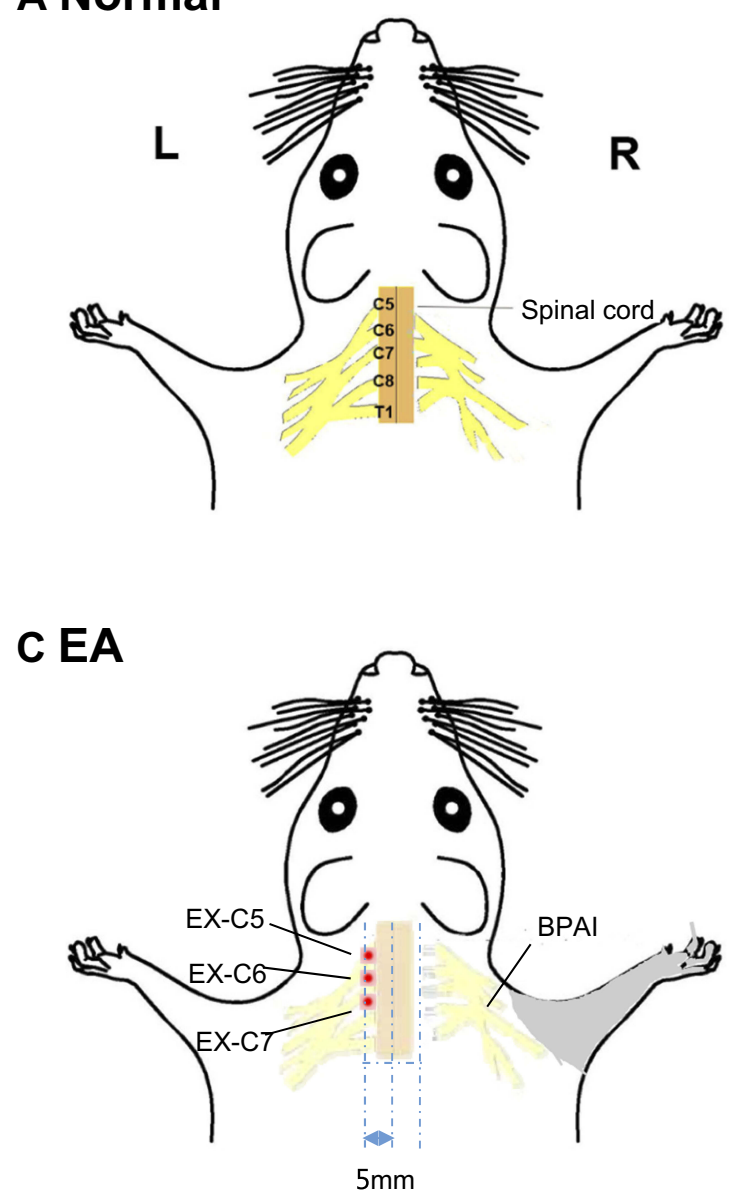

B Model

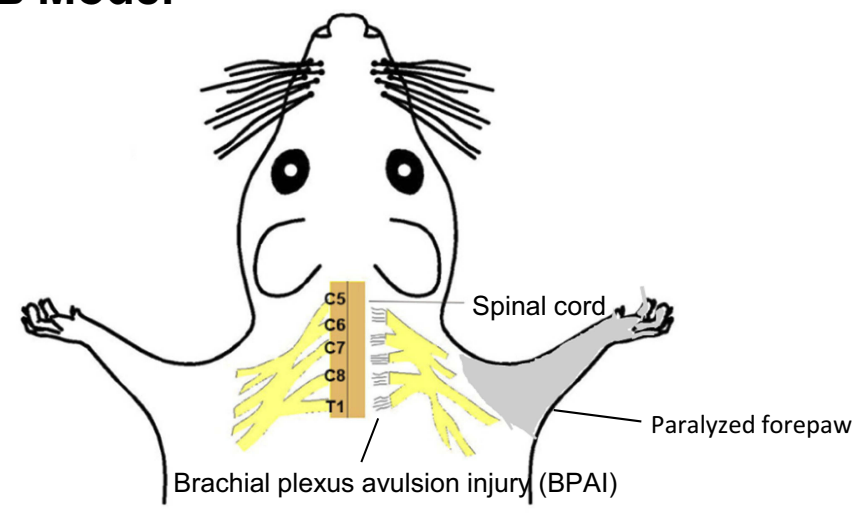

D Sham EA

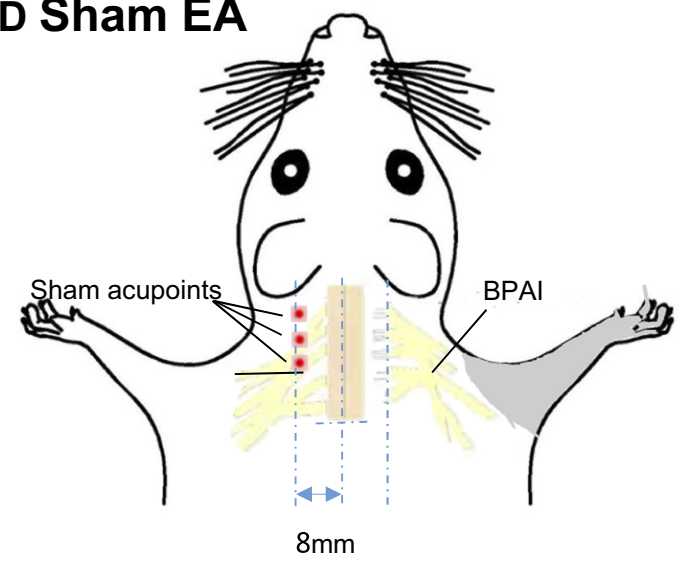

Figure I Schematic of the animal's groups. The rats were randomly divided into four groups (eight rats in each group): normal group, model group, electroacupuncture (EA) group, and sham electroacupuncture (sham EA) group. (A) Normal group: No particular-operation and therapeutic intervention was applied. (B) Model group: Nerve roots of $\mathrm{C} 5, \mathrm{C} 6, \mathrm{C7}, \mathrm{C} 8$, and $\mathrm{TI}$ on the right side were identified and avulsed from the spinal cord. (C) EA group: electroacupuncture were applied to the left side of the cervical EX-C5, EX-C6, and EX-C7 "jiaji" points ( $5 \mathrm{~mm}$ lateral to the C5-C7 cervical spine on the left side). (D) Sham EA group: the acupoints were $3 \mathrm{~mm}$ lateral to the C5-C7 cervical "Jiaji” acupoints without electrical output.

Abbreviations: L, left; R, right. C5-8, cervical vertebra 5-8, TI, thoracic vertebra I, EX-C5-7, cervical "jiaji” points (C5-7), the grey shadow area indicated the paralysed forepaws after BPAI.

had received adaption training for 3 days prior to the first intervention.

In the sham EA group, the environment was the same as previously described, while the acupoints were $3 \mathrm{~mm}$ lateral to the acupoints applied in the EA group without electrical output (Figure 1D). No particular therapeutic intervention was applied in the normal and model groups.

\section{Mechanical Withdrawal Threshold Measurement}

The mechanical withdrawal threshold (MWT) of the intact forepaw was tested at the baseline and on days 3, 7, 14, 21, $28,56,84$, and 112 subsequent to BPAI. The timeline is shown in Figure 2. Prior to the first test, all of the rats were trained for 5 days per week for 2 weeks.

Before testing, each rat was placed in an isolated clear plastic cage on an elevated mesh platform $(0.6 \mathrm{~cm} \times$ $0.6 \mathrm{~cm}$ ) for 20 mins for acclimation. The MWT was assessed with von Frey filaments (Stoelting Co., USA). Stepwise upgrading filaments were applied perpendicularly to the lateral plantar surface of the intact forepaw with sufficient force for 6-8 s, according to the method described by Chaplan et al. ${ }^{22} \mathrm{~A}$ positive response was described as an onset of forepaw withdrawal. ${ }^{23}$ The lowest force that triggered a positive response was recorded as the result. Testing with filament each scale was repeated 5 times. If the rat showed at least two positive responses, 


\section{Mechanical Withdrawal Threshold (MWT) Measurements}

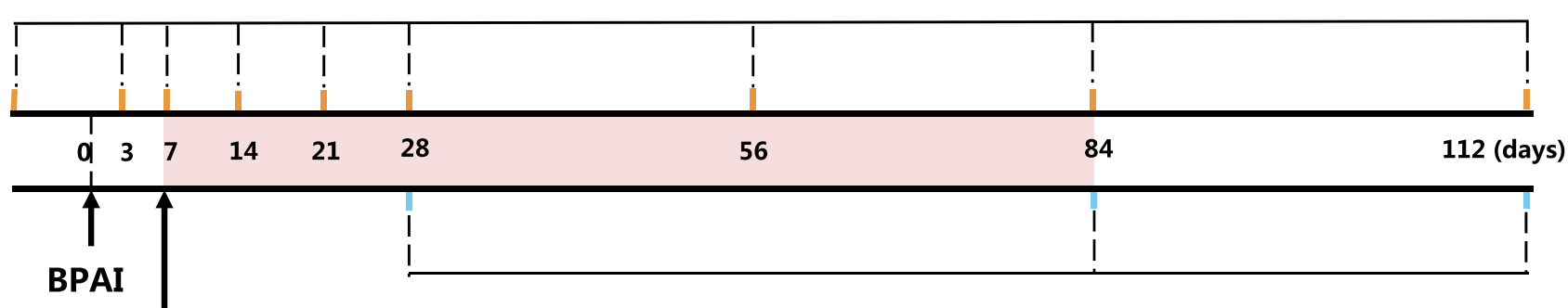

EA/Sham EA

${ }^{18}$ F-FDG PET/CT Scanning

Figure 2 Timeline of the protocol. The diagram showed the timeline of brachial plexus avulsion injury (BPAI) modeling, mechanical withdrawal threshold (MWT) measurements, electroacupuncture (EA) treatment, and PET/CT scans over the II2-day experiment. The MWT measurements of the left (intact) forepaw were conducted at baseline and on days $3,7,14,21,28,56,84$, and II2, respectively, following global BPAI of the right side. ${ }^{18}$ F-FDG PET/CT scans of the rats' brains were performed on days 28,84 , and II 12 following BPAI. The pink shadow area indicated the intervention duration of electroacupuncture (EA) or sham EA.

Abbreviations: MWT, mechanical withdrawal threshold; BPAI, brachial plexus avulsion injury; ${ }^{18} \mathrm{~F}-\mathrm{FDG},{ }^{18} \mathrm{~F}$-fluorodeoxyglucose; PET/CT, positron emission tomographycomputed tomography; BPAI = brachial plexus avulsion injury

the filament bending force was recorded as the MWT. If the response was negative, the filament with the nexthigher bending force was then applied.

\section{${ }^{18}$ F-FDG PET/CT Scan}

${ }^{18} \mathrm{~F}-\mathrm{FDG}$ PET/CT scans were performed at the end of the fourth, twelfth, and sixteenth weeks following global BPAI (Figure 2). To enhance the brain absorption of the tracers, all of the rats were fasted overnight before scanning. An injection of $0.5 \mathrm{~m} \mathrm{Ci} 18 \mathrm{~F}-\mathrm{FDG}$ was administered through the tail vein, and the rats were maintained for 30 mins for tracer distribution and noise control. The rats were then placed on a PET/CT R4 bed (Siemens Inc., USA) in a prone position. During scanning, each rat was stabilised using a cellophane tape and anesthetised with halothane gas (an induction dose of 5\% and a maintenance dose of $1.5 \%)$. Attenuation correction and anatomical delineation were performed. The images were acquired with a $128 \times 128$ matrix, recombined in OSEM3D mode. Brain images of cross-sectional, coronal, and sagittal views were obtained. The PET/CT acquisition parameters were as follows: spherical tube voltage $=80 \mathrm{kV}$, current $=500$ $\mu \mathrm{A}$, and time $=492 \mathrm{~s}$.

\section{Data Processing}

All of the image processing procedures and analyses were performed with Statistical Parametric Mapping 8 (SPM8) toolbox (http://www.fil.ion.ucl.ac.uk/spm/) based on the MATLAB 2014a platform (MathWorks, Inc., Natick, MA, USA). First, the raw DICOM format of the PET/CT images was converted into a NIFTI format using ImageJ software (Image Processing and Analysis in Java, National
Institutes of Health, Bethesda, MD, USA). Second, the voxels were upscaled by a factor of 10 , which was adequate for the SPM8 algorithm. ${ }^{24}$ The PET/CT images were reformatted to isometric voxels $\left(2 \times 2 \times 2 \mathrm{~mm}^{3}\right)$ and normalised to the standard template. Finally, the images were smoothed with a Gaussian kernel of $4 \mathrm{~mm}$ (full width at half maximum) of twice as the voxel size.

\section{Statistical Analysis}

SPSS 22.0 software (SPSS Inc.) was used for the data analysis. The results were expressed as mean \pm standard deviation (95\% confidence interval). Repetitive measure analysis of variance (ANOVA) was used to analyse the MWT data at different time points, followed by the least significant difference (LSD) post hoc test between two groups. Two-tailed $\mathrm{p}<0.05$ was considered statistically significant.

After raw data preprocessing, a two-sample $t$-test was used to calculate changes of standard uptake values (SUVs) among different groups at the end of the fourth, twelfth, and sixteenth weeks following global BPAI with a significance level of $\mathrm{p}=0.005$.

\section{Results}

\section{Animals}

All of the rats were in a normal active condition before BPAI. After C4-T1 laminectomy, the rats showed complete paralysis of their right forepaws. No obvious abnormal foraging activity or no infections were observed, while ptosis and concave eyeballs (positive sign of Horner's syndrome) were visible (Figure S1A). Half of the rats in the model and sham-EA groups showed 
autotomic behaviour of biting their toes (Figure S1B and Table S1).

\section{Mechanical Withdrawal Threshold Measurement}

There was no significant difference among the 4 groups at the baseline ( $p>0.05$ ). After BPAI, the MWT of the rats' left (intact) forepaws sharply decreased in the model, sham EA, and EA groups, gradually increased to a certain degree, and lasted throughout the remaining observational process.

During the 112-day observation, the MWT of the left (intact) forepaws in the normal group was significantly higher than that in the model group $(p<0.001)$. Since day 14 post-BPAI, the MWT of the left (intact) forepaws in the EA group started to increase and was significantly higher than that in the sham EA group, and lasted until day 112 (day 14, $<<0.05$; days 21-112, $\mathrm{p}<0.001$ ). No significant difference was found between the sham EA and model groups during the observation $(\mathrm{p}>0.05)$ (Figure 3 and Table 1).

\section{Brain Metabolism}

Comparisons between the normal and model groups and between the sham EA and EA groups were as follows:

(1) Sensorimotor-related brain regions: During the 112day observation, the ${ }^{18}$ F-FDG uptake value in the model group continuously decreased in the right somatosensory cortex, compared with the normal group (Tables S4, S8 and $\underline{\mathrm{S} 12}, \underline{\text { Figures } \mathrm{S} 4}, \underline{\mathrm{S} 8}$ and $\underline{\mathrm{S} 12}$ ). Compared with the sham EA group, the ${ }^{18}$ F-FDG uptake increased in the right somatosensory and motor cortices (contralateral to the intact limb) in the EA group on day 28 (4 weeks) (Figure 4A and Table 2). On day 84 (12 weeks), ${ }^{18}$ F-FDG uptake increased in the bilateral somatosensory cortices and decreased in the bilateral motor cortices (Figure 4B and Table 2). On day 112 (16weeks), ${ }^{18}$ F-FDG uptake increased in the superior colliculus and dorsolateral thalamus and decreased in the left somatosensory cortex (Figure 4C and Table 2).

(2) Pain-related brain regions: Compared with the normal group, lower ${ }^{18}$ F-FDG uptake value were noted in bilateral insular cortices in the model group during the

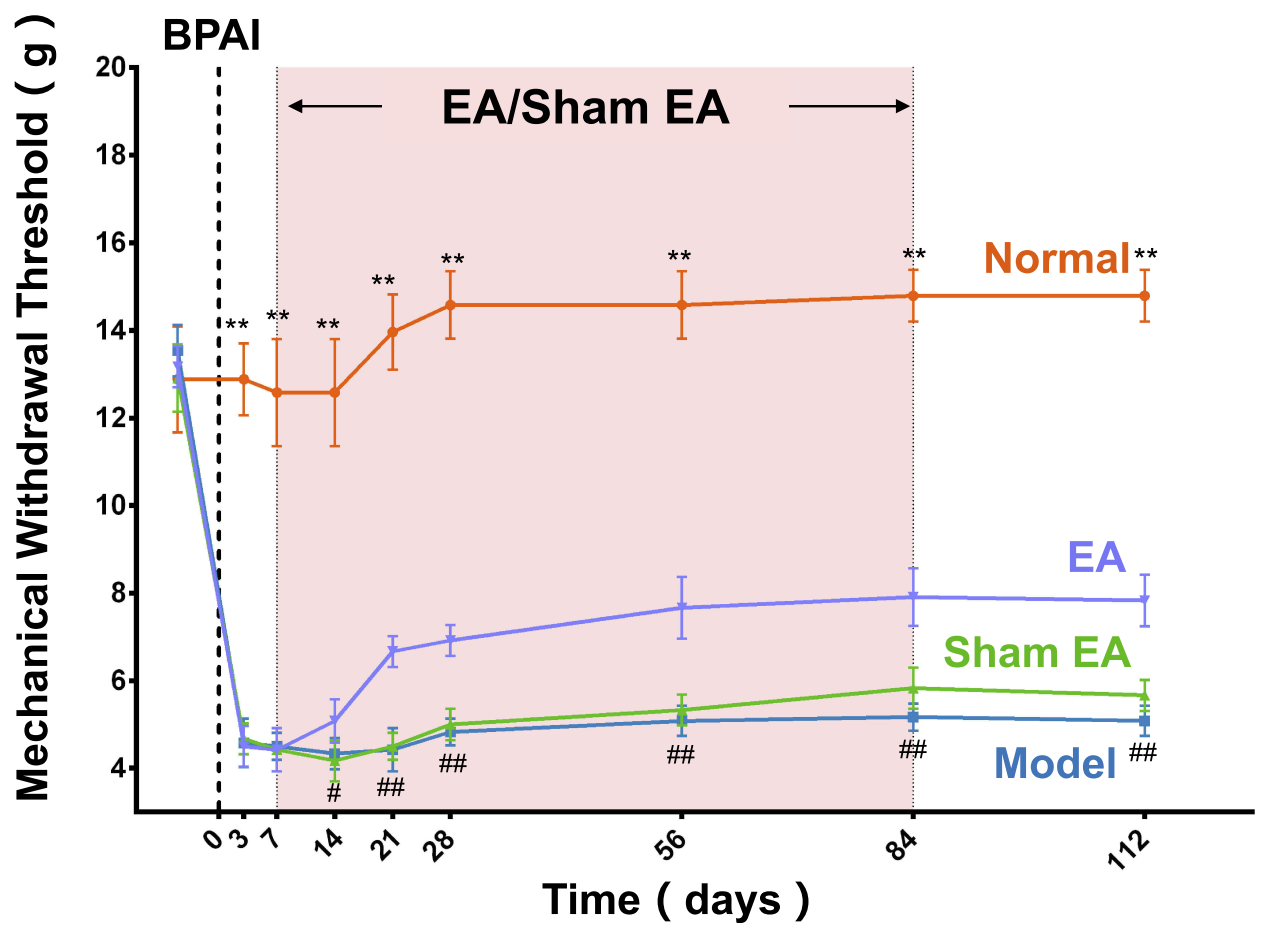

Figure 3 Mechanical withdrawal threshold of the intact forepaw in the four groups. There was no significant difference among the normal, model, sham EA, and EA groups at the baseline ( $p>0.05$ ). After BPAI, the MWT of the left (intact) forepaws sharply decreased in the model, sham EA, and EA groups, gradually increased to a certain degree and lasted throughout the remaining observational process. During the II2-day observation, the MWT of the left (intact) forepaw in the normal group was significantly higher than that in the model group $(\mathrm{p}<0.001)$. Since day 14 post-BPAl, the MWT of the left (intact) forepaw in the EA group started to increase and was significantly higher than that in the sham EA group, and lasted until day II 2 (day I4, $p<0.05$; days $21-112, p<0.00 I$ ). No significant difference was found between the sham EA and model groups during the observation $(p>0.05)$. The points and bars showed mean and standard deviation. The dotted line indicated when establishing the model of BPAl. The pink shadow area represented the duration of EA/sham EA intervention. ${ }^{* *}$ Indicated significant differences between the normal and model groups at the same time point $(\mathrm{p}<0.00 \mathrm{I}) .{ }^{\#}$ and \#\# Indicated significant differences between the EA and sham EA groups at the same time point (\#, $\left.p<0.05 ;{ }^{\#}, \mathrm{p}<0.00 \mathrm{I}\right)$.

Abbreviations: EA, electroacupuncture; BPAI, brachial plexus avulsion injury; MWT, mechanical withdrawal threshold. 
Table I Results of Mechanical Withdrawal Threshold (MWT) of the Non-Injured (Left) Forepaw in Four Groups at Different Timepoints Following BPAI (g) (Mean \pm SD $(95 \% \mathrm{Cl})$ )

\begin{tabular}{|l|l|l|l|l|}
\hline Group & Normal & Model & Sham EA & EA \\
\hline Baseline & $12.88 \pm 1.21(11.87,13.88)$ & $13.54 \pm 0.59(13.05,14.03)$ & $12.91 \pm 0.77(12.27,13.56)$ & $13.17 \pm 0.47(12.77,13.56)$ \\
Day 3 & $12.88 \pm 0.82(12.19,13.56)$ & $4.58 \pm 0.56(4.12,5.05) * *$ & $4.67 \pm 0.36(4.37,4.96)$ & $4.50 \pm 0.47(4.11,4.89)$ \\
Day 7 & $12.58 \pm 1.22(11.56,13.60)$ & $4.50 \pm 0.31(4.24,4.76) * *$ & $4.42 \pm 0.50(4.00,4.83)$ & $4.42 \pm 0.50(4.00,4.83)$ \\
Day 14 & $12.58 \pm 1.22(11.56,13.60)$ & $4.33 \pm 0.36(4.04,4.63) * *$ & $4.17 \pm 0.47(3.77,4.56)$ & $5.08 \pm 0.50(4.67,5.50) \#$ \\
Day 2I & $13.96 \pm 0.86(13.24,14.68)$ & $4.42 \pm 0.50(4.00,4.83) * *$ & $4.50 \pm 0.31(4.24,4.76)$ & $6.67 \pm 0.36(6.37,6.96)$ \\
Day 28 & $14.58 \pm 0.77(13.94,15.23)$ & $4.83 \pm 0.31(4.58,5.09) * *$ & $5.00 \pm 0.36(4.70,5.30)$ & $6.92 \pm 0.35(6.63,7.21)$ \\
Day 56 & $14.58 \pm 0.77(13.94,15.23)$ & $5.08 \pm 0.35(4.80,5.37) * *$ & $5.33 \pm 0.36(5.04,5.63)$ & $7.67 \pm 0.71(7.07,8.26)$ \\
Day 84 & $14.79 \pm 0.59(14.30,15.28)$ & $5.17 \pm 0.31(4.91,5.42) * *$ & $5.83 \pm 0.47(5.44,6.23)$ & $7.91 \pm 0.66(7.36,8.47)$ \\
Day II2 & $14.79 \pm 0.59(14.30,15.28)$ & $5.08 \pm 0.35(4.79,5.37) * *$ & $5.67 \pm 0.36(5.37,5.96)$ & $7.83 \pm 0.59(7.34,8.33)$ \\
\hline
\end{tabular}

Notes: **Indicated significant differences between the normal and model groups at the same time point $(p<0.00 \mathrm{I}) .{ }^{\#}$ and ${ }^{\# \#}$ Indicated significant differences between the EA and sham EA groups at the same time point ( $\left.{ }^{\#}, \mathrm{p}<0.05 ;{ }^{\# \#}, \mathrm{p}<0.00 \mathrm{I}\right)$.

Abbreviations: BPAl, brachial plexus avulsion injury; $\mathrm{EA}$, electroacupuncture; $\mathrm{Cl}$, confidence interval.

observation (Tables S4,$\underline{\mathrm{S} 8}$ and $\underline{\mathrm{S} 12}, \underline{\text { Figures S4}}, \underline{\mathrm{S} 8}$ and S12). Compared with the sham EA group, ${ }^{18} \mathrm{~F}-\mathrm{FDG}$ uptake decreased in the bilateral periaqueductal grey matter in the EA group on day 28 (4 weeks) (Figure 4A and Table 2). On day 84 (12 weeks), ${ }^{18}$ F-FDG increased in the cingulate cortex and decreased in the bilateral insular (Table 2). On day 112 (16weeks), ${ }^{18}$ F-FDG uptake increased in the bilateral insular (Table 2).

(3) Emotion- and cognition-related brain regions: Compared with the normal group, lower ${ }^{18} \mathrm{~F}$-FDG uptake values were noted in right dorsal posterior hippocampus in the model group during the observation. Higher ${ }^{18}$ F-FDG uptake values were observed in the orbitofrontal cortex on day 28 (4 weeks) and 84 (12 weeks), while lower ${ }^{18} \mathrm{~F}$-FDG uptake values were seen on day 112 (16 weeks) (Tables S4, $\underline{\mathrm{S} 8}$ and $\underline{\mathrm{S} 12}$, Figures $\underline{\mathrm{S}} 4, \underline{\mathrm{S} 8}$ and $\underline{\mathrm{S} 12})$. Compared with the sham EA group, ${ }^{18} \mathrm{~F}-\mathrm{FDG}$ uptake increased in the right medial prefrontal and orbitofrontal cortices and decreased in the left ventral hippocampus in the EA group on day 28 (4 weeks) (Figure 4A and Table 2). On day 84 (12 weeks), ${ }^{18} \mathrm{~F}$-FDG increased in the medial prefrontal cortex, orbitofrontal cortex, and ventral hippocampus, and decreased in the right amygdala (Figure 4B and Table 2). On day 112 (16 weeks), ${ }^{18}$ F-FDG uptake increased in the dorsolateral thalamus, retrosplenial cortex, and posterior dorsal hippocampus, and decreased in the orbitofrontal cortex and ventral hippocampus (Figure 4C and Table 2).

The metabolism results at all of the time points between either group were included in the supplementary materials (Supplementary Tables S2-S13 and Supplementary Figures $\underline{\text { S2-S13). }}$.

\section{Discussion}

Chronic pain is a multidimensional experience that continually affects the sensory, motor, emotional, cognitive, and other functions. ${ }^{25-27}$ Neuropathic pain following BPAI is one of the most intractable types of chronic pain. ${ }^{28-31}$ Studies have demonstrated that abnormal brain activity is an important aspect of its occurrence/persistence and might be associated with its severity. ${ }^{32,33}$ Therefore, interventions that change brain plasticity may be potentially helpful for relieving neuropathic pain.

Acupuncture is a popular technique in traditional Chinese medicine for various dysfunctions. ${ }^{34,35}$ Its combined use with electrical output (EA) has been increasingly applied for the treatment of inflammatory pain. ${ }^{31}$ EA stimulation at a frequency of $2 / 15 \mathrm{~Hz}$ is commonly used for the treatment of chronic pain. Chen et al applied 2/15 EA stimulation in bilateral "Jiaji" acupoints in chronic constriction injury rats. ${ }^{36}$ Wang et al used 2/15 Hz EA stimulation in "Zusanli" (ST 36) and "Yanglingquan" (GB 34) in rats with chronic constrictive injury (CCI) to observe the accumulative analgesic effect of EA. ${ }^{37}$ In addition, 2/ $15 \mathrm{~Hz}$ EA was also reported for treating other types of pain. Feng et al used $2 / 15 \mathrm{~Hz}$ EA stimulation in a rat model of post-laparotomy pain. ${ }^{38}$ Zou et al applied 2/15 Hz EA stimulation in "jiaji” acupoints of rabbits to treat lumbar disc degeneration. ${ }^{39}$ For these reasons, $2 / 15 \mathrm{~Hz}$ was used in the present study. But the mechanism underlying the analgesic effects of $2 / 15 \mathrm{~Hz}$ EA on chronic pain might be complicated. There have studies showing that opioid substances were involved in the acupuncture analgesia. ${ }^{40}$ Han et al reported that the analgesic effect of $2 \mathrm{~Hz}$ EA was related with increased release of endomorphin (EM), but $100 \mathrm{~Hz}$ EA did not. ${ }^{41}$ However, one study 


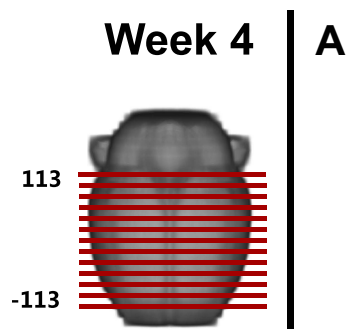

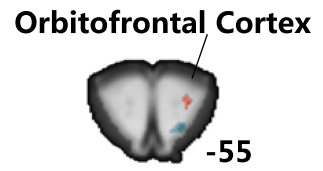

Motor Cortex
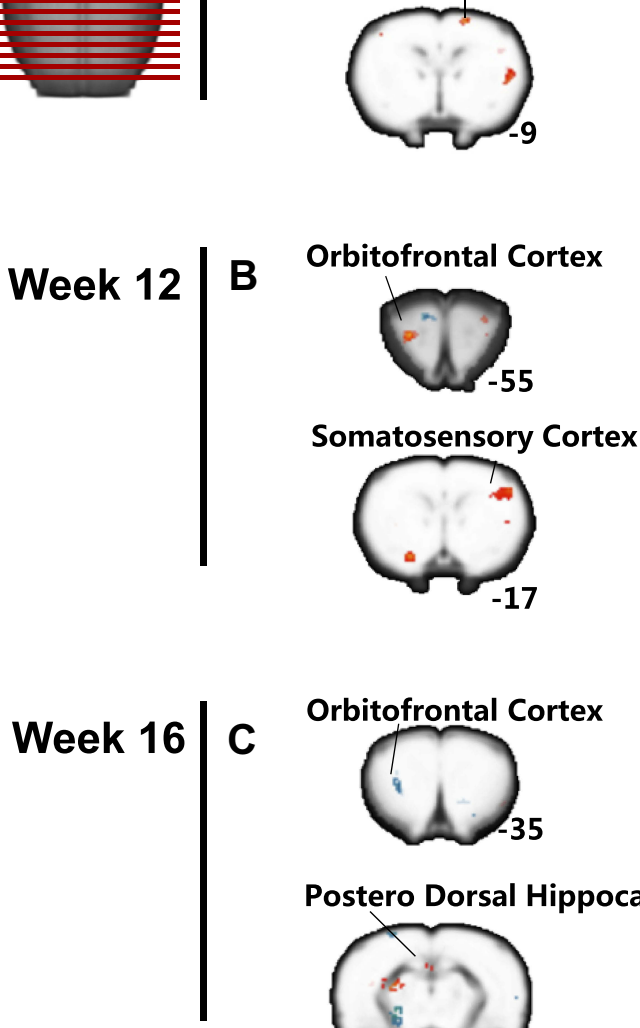

Orbitofrontal Cortex

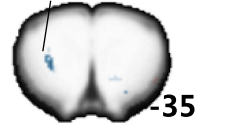

Postero Dorsal Hippocampus

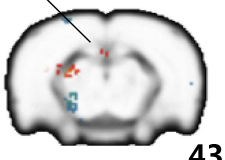

43
Medial Prefrontal Cortex

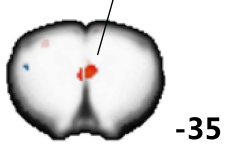

Ventral Hippocampus

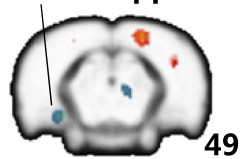

Medial Prefrontal Cortex

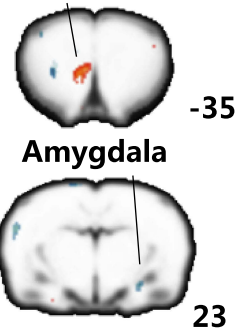

Somatosensory Cortex

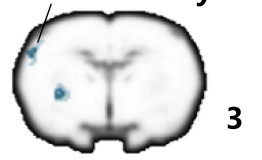

Superior Colliculus

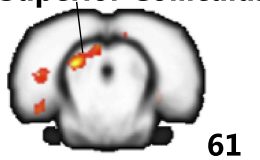

61
Somatosensory Cortex

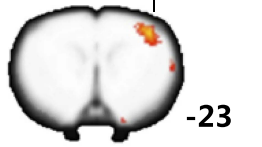

Periaqueductal Grey Matter

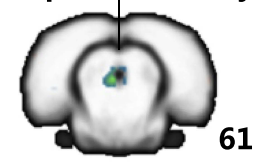

Caudate Putamen

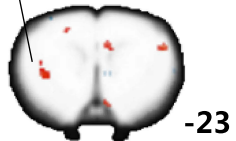

Ventral Hippocampus

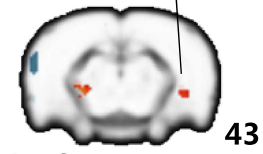

Dorsolateral Thalamus

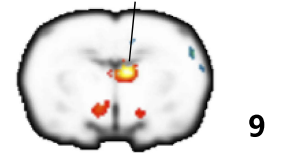

Retro-splenial Cortex

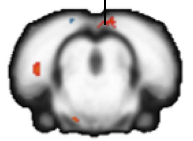

69

L

$-3 \quad 3$

Figure 4 Main brain regions showing significant differences in the ${ }^{18} \mathrm{~F}-\mathrm{FDG}$ uptake value between the EA and the sham EA groups (EA vs sham EA) on days 28 (A), 84 (B), and I I 2 (C) after global BPAI. L = left hemisphere; EA = electroacupuncture; BPAI = brachial plexus avulsion injury; ${ }^{18} \mathrm{~F}$-FDG $={ }^{18} \mathrm{~F}$-fluorodeoxyglucose. The warm colour indicated significantly higher ${ }^{18} \mathrm{~F}$-FDG uptake in the EA group than that in the sham EA group, while the cold colour indicated a significantly lower ${ }^{18} \mathrm{~F}$-FDG uptake in the EA group. Axial brain slices were showed in three columns on the right and slice number were labeled at bottom right.

proposed that the mechanism of $2 / 15 \mathrm{~Hz}$ EA in the treatment of post-laparotomy pain was potentially related to an opioid-independent pathway. ${ }^{38}$ The expression of pMEK1 in the hypothalamus was gradually down-regulated following continuous intervention of $2 / 15 \mathrm{~Hz}$ EA and the effect was time dependent and cumulative. ${ }^{42}$

In the behavioural assessment, MWT was used to detect mechanical allodynia, which has been frequently used in the sensation tests following brachial plexus nerve, median, and ulnar nerves, and sciatic nerve injuries in previous studies. ${ }^{43-46}$ BPAI-induced pain in the injured forelimb subsequently caused central sensitisation and facilitation of pain sensation. ${ }^{47}$ In the present sensory tests, the mechanical threshold of the intact forepaw was measured to quantitatively measure neuropathic pain following BPAI. ${ }^{44}$ This was because the sensorimotor function of the affected limb completely lost after BPAI. Studies have demonstrated hypersensitisation in the intact limbs following BPAI and the pain threshold decreased. Application of EA on the cervical "Jiaji" EX-C5, EX-C6, and EX-C7 point can relieve this hypersensitisation. The pain threshold of the intact forepaws was significantly elevated and the effect persisted until 4 weeks after the intervention ceased.

In our preliminary study, recovery of sensory function following sciatic nerve injury-repair also improved after the application of EA. Synchronised activation was found in the somatosensory and pain-related brain areas using 
Table 2 Brain Regions of Significant Metabolism Changes on Days 28, 84, and II2 After Brachial Plexus Avulsion Injury (BPAl) of Electroacupuncture (EA) Group Compared with Sham Electroacupuncture (Sham EA) Group $(P<0.005)$

\begin{tabular}{|c|c|c|c|c|c|c|c|}
\hline \multirow[t]{2}{*}{ Timeline } & \multirow{2}{*}{$\begin{array}{l}\text { Metabolism changes EA-group vs } \\
\text { sham-EA group }\end{array}$} & \multirow[t]{2}{*}{ Brain regions } & \multicolumn{3}{|c|}{ MNI coordinates } & \multirow[t]{2}{*}{ Extent } & \multirow[t]{2}{*}{ t-value } \\
\hline & & & $\mathbf{x}$ & $y$ & $\mathbf{z}$ & & \\
\hline \multicolumn{8}{|c|}{ Sensorimotor related regions } \\
\hline Day 28 & Positive & $\begin{array}{l}\text { R_Cortex_Somatosensory } \\
\text { R_Cortex_Motor }\end{array}$ & $\begin{array}{l}44 \\
42\end{array}$ & $\begin{array}{l}30 \\
26\end{array}$ & $\begin{array}{l}-33 \\
-63\end{array}$ & $\begin{array}{l}1253 \\
323\end{array}$ & $\begin{array}{l}6.114 \\
5.942\end{array}$ \\
\hline Day 84 & $\begin{array}{l}\text { Positive } \\
\text { Negative }\end{array}$ & $\begin{array}{l}\text { R_Cortex_Somatosensory } \\
\text { L_Cortex_Somatosensory } \\
\text { R_Cortex_Motor } \\
\text { L_Cortex_Motor }\end{array}$ & $\begin{array}{l}54 \\
-61 \\
9 \\
-42\end{array}$ & $\begin{array}{l}17 \\
22 \\
26 \\
26\end{array}$ & $\begin{array}{l}-57 \\
-37 \\
-43 \\
-75\end{array}$ & $\begin{array}{l}258 \\
81 \\
40 \\
31\end{array}$ & $\begin{array}{l}4.498 \\
4.279 \\
-3.908 \\
-3.786\end{array}$ \\
\hline Day 112 & $\begin{array}{l}\text { Positive } \\
\text { Negative }\end{array}$ & $\begin{array}{l}\text { L_Superior_Colliculus } \\
\text { R_Thalamus_Midline_Dorsal } \\
\text { L_Thalamus_Dorsolateral } \\
\text { L_Cortex_Somatosensory }\end{array}$ & $\begin{array}{l}-24 \\
9 \\
-30 \\
-61\end{array}$ & $\begin{array}{l}1 \\
-3 \\
-3 \\
7\end{array}$ & $\begin{array}{l}21 \\
-31 \\
1 \\
-39\end{array}$ & $\begin{array}{l}340 \\
152 \\
126 \\
145\end{array}$ & $\begin{array}{l}7.396 \\
9.483 \\
4.673 \\
-5.509\end{array}$ \\
\hline \multicolumn{8}{|c|}{ Pain-related regions } \\
\hline Day 28 & Negative & $\begin{array}{l}\text { R_Periaqueductal_Grey } \\
\text { L_Periaqueductal_Grey }\end{array}$ & $\begin{array}{l}5 \\
-3\end{array}$ & $\begin{array}{l}-7 \\
-7\end{array}$ & $\begin{array}{l}19 \\
23\end{array}$ & $\begin{array}{l}219 \\
120\end{array}$ & $\begin{array}{l}-4.578 \\
-6.988\end{array}$ \\
\hline Day 84 & $\begin{array}{l}\text { Positive } \\
\text { Negative }\end{array}$ & $\begin{array}{l}\text { R_Cortex_Cingulate } \\
\text { R_Cortex_Insular }\end{array}$ & $\begin{array}{l}9 \\
71\end{array}$ & $\begin{array}{l}15 \\
-20\end{array}$ & $\begin{array}{l}-61 \\
-33\end{array}$ & $\begin{array}{l}17 \\
9\end{array}$ & $\begin{array}{l}3.336 \\
-3.365\end{array}$ \\
\hline DayII2 & Positive & $\begin{array}{l}\text { L_Cortex_Insular } \\
\text { R_Cortex_Insular } \\
\text { L_Cortex_Insular }\end{array}$ & $\begin{array}{l}-67 \\
50 \\
-67\end{array}$ & $\begin{array}{l}-17 \\
-17 \\
-23\end{array}$ & $\begin{array}{l}-33 \\
-73 \\
-41\end{array}$ & $\begin{array}{l}3 \\
2 \\
1\end{array}$ & $\begin{array}{l}-3.245 \\
3.095 \\
3.026\end{array}$ \\
\hline \multicolumn{8}{|c|}{ Emotion and cognition related brain regions } \\
\hline Day 28 & $\begin{array}{l}\text { Positive } \\
\text { Negative }\end{array}$ & $\begin{array}{l}\text { R_Cortex_Medial_Prefrontal } \\
\text { R_Cortex_Orbitofrontal } \\
\text { L_Hippocampus_Ventral }\end{array}$ & $\begin{array}{l}3 \\
28 \\
-42\end{array}$ & $\begin{array}{l}3 \\
11 \\
-32\end{array}$ & $\begin{array}{l}-75 \\
-93 \\
11\end{array}$ & $\begin{array}{l}87 \\
55 \\
106\end{array}$ & $\begin{array}{l}3.936 \\
3.689 \\
-4.645\end{array}$ \\
\hline Day 84 & $\begin{array}{l}\text { Positive } \\
\text { Negative }\end{array}$ & $\begin{array}{l}\text { L_Cortex_Medial_Prefrontal } \\
\text { L_Cortex_Orbitofrontal } \\
\text { R_Hippocampus_Ventral } \\
\text { R_Amygdala }\end{array}$ & $\begin{array}{l}-11 \\
-28 \\
50 \\
36\end{array}$ & $\begin{array}{l}-7 \\
7 \\
-20 \\
-38\end{array}$ & $\begin{array}{l}-75 \\
-95 \\
5 \\
-19\end{array}$ & $\begin{array}{l}101 \\
38 \\
37 \\
38\end{array}$ & $\begin{array}{l}4.467 \\
5.522 \\
3.765 \\
-4.499\end{array}$ \\
\hline Dayl I2 & Positive & $\begin{array}{l}\text { L_Hippocampus_Subiculum } \\
\text { R_Cortex_Retrosplenial } \\
\text { R_Hippocampus_Postero_Dorsal } \\
\text { L_Hippocampus_Ventral } \\
\text { L_Cortex_Orbitofrontal }\end{array}$ & $\begin{array}{l}-52 \\
15 \\
48 \\
-26 \\
-36\end{array}$ & $\begin{array}{l}-7 \\
34 \\
-5 \\
-44 \\
-1\end{array}$ & $\begin{array}{l}25 \\
29 \\
13 \\
1 \\
-77\end{array}$ & $\begin{array}{l}246 \\
47 \\
39 \\
122 \\
39\end{array}$ & $\begin{array}{l}4.927 \\
3.547 \\
4.168 \\
-4.059 \\
-3.485\end{array}$ \\
\hline
\end{tabular}

Notes: Positive indicated EA group > sham EA group, and negative indicated EA group < sham EA group.

small animal fMRI. ${ }^{48}$ We also used small animal PET/CT to explore metabolism in the brain-related BPAI-induced neuropathic pain. ${ }^{19}$ In the present study, the changes of brain in EA-treated neuropathic pain rats were detected using PET/CT scans. Both the immediate and aftereffects of the metabolic mechanisms were investigated.

The ${ }^{18}$ F-FDG uptake values in brain regions including the bilateral somatosensory and motor cortices were observed in the EA group. Metabolism particularly increased in the right somatosensory cortex. This suggested that the application of EA increased the activity of the sensorimotor cortex corresponding to the intact limbs. The enhancement of the intact limb cortex compensated the function of affected limbs. EA can also regulate the pain-related regions, bilateral periaqueductal grey matter, and insular cortex. This post-effect of EA also continued until 4 weeks after the intervention ceased. 
With the progress in neuroanatomy, sensory neuropsychology, functional imaging, and brain science, neuropathic pain has been proved to be related to different psychophysiological processes, such as sensorimotor, cognition, and emotion. ${ }^{49} \mathrm{De}$ Ridder et al showed that neuropathic pain was associated with plasticity of the somatosensory cortex. ${ }^{32}$ Flor et al reported that neuropathic pain due to amputation was related to expansion of the adjacent region, ${ }^{12,50}$ which was consistent with our previous research. ${ }^{19,51}$ Studies also revealed that cortical changes were not restricted to the sensorimotor cortex, but also an involved extensive range of areas, including the thalamus, anterior insula, and others. ${ }^{52-54}$ The thalamus is the main relay of sensory and spinal nerve pathways (spinothalamic tract), which is important for the development of deafferentation pain. Evidence suggested that neuropathic pain usually occurred in areas of hypesthesia, and therefore thalamic hypoactivity might be the result of sensory deafferentation. ${ }^{55}$ In the present study, we also noted that BPAI-induced neuropathic pain and the effect of EA were related to metabolic changes in the brain regions governing sensorimotor, pain, emotion, and cognition functions.

\section{Conclusion}

The present study demonstrated the beneficial effects of EA for relieving BPAI-induced neuropathic pain in rats. These effects may persist for 4 weeks after the cessation of intervention. In the BPAI rats, decreased metabolism was noted in extended brain areas related to sensorimotor, pain, emotion, and recognition. EA intervention might inhibit maladaptive plasticity in brain areas governing multidimensional functions, especially in sensorimotor and cognition-related cortices. However, the effect of sham EA on brain activity was divergent and inconsistent.

\section{Acknowledgments}

This study was supported by Shanghai Education Committee (Grant No.: A2-P1600325); the Shanghai Rising-Star Program (Grant No.: 19QA1409000); Shanghai Municipal Commission of Health and Family Planning (Grant No.: 2018YQ02); Shanghai "Rising Stars of Medical Talent" Youth Development Program (Grant No.: RY411.19.01.10) and Graduate Innovation Ability Project of Shanghai University of Traditional Chinese Medicine (Grant No.: Y2019067).

\section{Disclosure}

The authors report no conflicts of interest in this work.

\section{References}

1. Zuo CT, Hua XY, Guan YH, Xu WD, Xu JG, Gu YD. Long-range plasticity between intact hemispheres after contralateral cervical nerve transfer in humans. $J$ Neurosurg. 2010;113(1):133-140. doi:10.3171/2010.1.JNS09448

2. Tantigate D, Wongtrakul S, Vathana $\mathrm{T}$, Limthongthang $\mathrm{R}$, Songcharoen P. Neuropathic pain in brachial plexus injury. Hand Surg. 2015;20(1):39-45. doi:10.1142/S0218810415500057

3. Pereira EA, Boccard SG, Linhares P, et al. Thalamic deep brain stimulation for neuropathic pain after amputation or brachial plexus avulsion. Neurosurg Focus. 2013;35(3):E7. doi:10.3171/2013.7.FOCUS1346

4. Kim JH, Shin SH, Lee YR, et al. Ultrasound-guided peripheral nerve stimulation for neuropathic pain after brachial plexus injury: two case reports. J Anesth. 2017;31(3):453-457. doi:10.1007/s00540-017-2315-5

5. Liu Y, Wang L, Meng C, Zhou Y, Lao J, Zhao X. A new model for the study of neuropathic pain after brachial plexus injury. Injury. 2017;48(2):253-261. doi:10.1016/j.injury.2016.11.007

6. Kuehn B. Chronic Pain Prevalence. JAMA. 2018;320(16):1632.

7. Volkow ND, McLellan AT. Opioid abuse in chronic pain-misconceptions and mitigation strategies. $N$ Engl J Med. 2016;374 (13):1253-1263. doi:10.1056/NEJMra1507771

8. Jackson T, Thomas S, Stabile V, Han X, Shotwell M, McQueen K. Prevalence of chronic pain in low-income and middle-income countries: a systematic review and meta-analysis. Lancet. 2015;385(Suppl 2):S10. doi:10.1016/S0140-6736(15)60805-4

9. Abdel-Aziz S, Ghaleb AH. Cervical spinal cord stimulation for the management of pain from brachial plexus avulsion. Pain Med. 2014;15(4):712-714. doi:10.1111/pme.12313

10. Teixeira MJ, Da Paz MGDS, Bina MT, et al. Neuropathic pain after brachial plexus avulsion-central and peripheral mechanisms. BMC Neurol. 2015;15(1):1-9. doi:10.1186/s12883-015-0329-x

11. Price TJ, Basbaum AI, Bresnahan J, et al. Transition to chronic pain: opportunities for novel therapeutics. Nat Rev Neurosci. 2018;19 (7):383-384. doi:10.1038/s41583-018-0012-5

12. Flor H, Nikolajsen L, Staehelin JT. Phantom limb pain: a case of maladaptive CNS plasticity? Nat Rev Neurosci. 2006;7(11):873-881. doi:10.1038/nrn1991

13. Bingel U, Quante M, Knab R, Bromm B, Weiller C, Buchel C. Subcortical structures involved in pain processing: evidence from single-trial fMRI. Pain. 2002;99(1-2):313-321. doi:10.1016/S03043959(02)00157-4

14. Chavez LM, Huang SS, MacDonald I, Lin JG, Lee YC, Chen YH. Mechanisms of acupuncture therapy in ischemic stroke rehabilitation: a literature review of basic studies. Int J Mol Sci. 2017;18(11):2270. doi:10.3390/ijms 18112270

15. Liu CZ, Kong J, Wang K. Acupuncture therapies and neuroplasticity. Neural Plast. 2017;2017:1-2.

16. Wang JY, Chen R, Chen SP, et al. Electroacupuncture reduces the effects of acute noxious stimulation on the electrical activity of pain-related neurons in the hippocampus of control and neuropathic pain rats. Neural Plast. 2016;2016:6521026. doi:10.1155/2016/6521026

17. Theysohn N, Choi KE, Gizewski ER, et al. Acupuncture-related modulation of pain-associated brain networks during electrical pain stimulation: a functional magnetic resonance imaging study. $J$ Altern Complement Med. 2014;20(12):893-900. doi:10.1089/acm.2014.0105

18. Oliveira CM, Lima FF, de Oliveira ML, et al. Evaluation of a technique for in vivo internal monitoring of $18 \mathrm{~F}$ within a Brazilian laboratory network. Radiat Prot Dosim. 2012;153 (1):100-105. doi:10.1093/rpd/ncs090

19. Shen J, Huo BB, Hua XY, et al. Cerebral (18)F-FDG metabolism alteration in a neuropathic pain model following brachial plexus avulsion: a PET/CT study in rats. Brain Res. 2019;1712:132-138. doi:10.1016/j.brainres.2019.02.005 
20. Fang Z. Atlas of acupuncture and moxibustion at shu point and manipulation in experimental rats. J Nanjing Railway Medical Coll. 1993;12 (1):19-21.

21. Liang S, Lin Y, Lin B, et al. Resting-state functional magnetic resonance imaging analysis of brain functional activity in rats with ischemic stroke treated by electro-acupuncture. J Stroke Cerebrovasc Dis. 2017;26 (9):1953-1959. doi:10.1016/j.jstrokecerebrovasdis.2017.06.018

22. Chaplan SR, Bach FW, Pogrel JW, Chung JM, Yaksh TL. Quantitative assessment of tactile allodynia in the rat paw. J Neurosci Methods. 1994;53(1):55-63. doi:10.1016/0165-0270(94)90144-9

23. Zhou DM, Zhuang Y, Chen WJ, Li W, Miao B. Effects of duloxetine on the toll-like receptor 4 signaling pathway in spinal dorsal horn in a rat model of diabetic neuropathic pain. Pain Med. 2018;19 (3):580-588. doi:10.1093/pm/pnx125

24. Tambalo S, Peruzzotti-Jametti L, Rigolio R, et al. Functional magnetic resonance imaging of rats with experimental autoimmune encephalomyelitis reveals brain cortex remodeling. $J$ Neurosci. 2015;35 (27):10088-10100. doi:10.1523/JNEUROSCI.0540-15.2015

25. Gao YH, Li CW, Wang JY, et al. Activation of hippocampal MEK1 contributes to the cumulative antinociceptive effect of electroacupuncture in neuropathic pain rats. BMC Complement Altern Med. 2016;16(1):517. doi:10.1186/s12906-016-1508-z

26. Hauck M, Schroder S, Meyer-Hamme G, et al. Acupuncture analgesia involves modulation of pain-induced gamma oscillations and cortical network connectivity. Sci Rep. 2017;7(1):16307. doi:10.1038/s41598017-13633-4

27. Wang JY, Chen SP, Gao YH, Qiao LN, Zhang JL, Liu JL. Effect of repeated electroacupuncture intervention on hippocampal ERK and p38MAPK signaling in neuropathic pain rats. Evid Based Complement Alternat Med. 2015;2015:641286.

28. Simon NG, Franz CK, Gupta N, Alden T, Kliot M. Central adaptation following brachial plexus injury. World Neurosurg. 2016;85:325-332. doi:10.1016/j.wneu.2015.09.027

29. Mohanty CB. Central plasticity in brachial plexus injury: a neural domino effect. World Neurosurg. 2016;86:22-24. doi:10.1016/j. wneu.2015.10.040

30. Liu B, Li T, Tang WJ, et al. Changes of inter-hemispheric functional connectivity between motor cortices after brachial plexuses injury: a resting-state fMRI study. Neuroscience. 2013;243:33-39. doi:10.1016/j.neuroscience.2013.03.048

31. Ciaramitaro P, Padua L, Devigili G, et al. Prevalence of neuropathic pain in patients with traumatic brachial plexus injury: a multicenter prospective hospital-based study. Pain Med. 2017;18(12):2428-2832. doi:10.1093/pm/pnw360

32. De Ridder D, Vanneste S, Van Laere K, Menovsky T. Chasing map plasticity in neuropathic pain. World Neurosurg. 2013;80(6):e1-e5. doi:10.1016/j.wneu.2012.12.009

33. Pawela CP, Biswal BB, Hudetz AG, et al. Interhemispheric neuroplasticity following limb deafferentation detected by resting-state functional connectivity magnetic resonance imaging (fcMRI) and functional magnetic resonance imaging (fMRI). Neuroimage. 2010;49(3):2467-2478. doi:10.1016/j.neuroimage.2009.09.054

34. Ju ZY, Wang K, Cui HS, et al. Acupuncture for neuropathic pain in adults. Cochrane Database Syst Rev. 2017;12:1-68.

35. Cun-Zhi L, Jie-Ping X, Lin-Peng W, et al. A randomized controlled trial of single point acupuncture in primary dysmenorrhea. Pain Med. 2014;15(6):910-920. doi:10.1111/pme.12392

36. Chen H, Huang M, Yu W, LIN D, LIN L. After effect of electroacupuncture at Jiaji acupoint on the protein expression of P2X4, P2X7 in chronic constriction injury rats. Rehabil Med. 2018;28 (1):37-40. doi:10.3724/SP.J.1329.2018.01037

37. Wang J, Chen S, Li Y, Meng F, Gao Y, Liu J. Observation on the accumulative analgesic effect of electroacupuncture and the expression of protein kinase $\mathrm{A}$ in hypothalamus and hippocampus in chronic pain or/and ovariectomized rats. Acupuncture Res. 2008;33 (2):80-87.
38. Feng XM, Mi WL, Xia F, et al. Involvement of spinal orexin A in the electroacupuncture analgesia in a rat model of post-laparotomy pain. BMC Complement Altern Med. 2012;12:225. doi:10.1186/ 1472-6882-12-225

39. Zou J, Huang G, Zhang Q, Gao Y, Wang B. Effects of electroacupuncture stimulation of "jiaji" (EX-B2) on expression of matrix metallo-proteinase-13 and tissue inhibitor of metalloproteinase-1 in intervertebral disc tissue in rabbits with lumbar intervertebral disc degeneration. Acupuncture Res. 2014;39 (3):192-197.

40. Mayer DJ. Acupuncture: an evidence-based review of the clinical literature. Annu Rev Med. 2000;51:49-63. doi:10.1146/annurev. med.51.1.49

41. Han J. New evidence to substantiate the frequency specificity of acupuncture-induced analgesia. Acupuncture Res. 2001;26 (3):225-227.

42. Gao YH, Li CW, Wang JY, et al. Activation of hippocampal MEK1 contributes to the cumulative antinociceptive effect of electroacupuncture in neuropathic pain rats. BMC Complement Altern Med. 2016;16(1):1-17. doi:10.1186/s12906-016-1508-z

43. Huang CT, Tsai YJ. Docosahexaenoic acid confers analgesic effects after median nerve injury via inhibition of c-Jun N-terminal kinase activation in microglia. $J$ Nutr Biochem. 2016;29(11):97-106. doi:10.1016/j.jnutbio.2015.11.009

44. Wang L, Yuzhou L, Yingjie Z, Jie L, Xin Z. A new rat model of neuropathic pain: complete brachial plexus avulsion. Neurosci Lett. 2015;589:52-56. doi:10.1016/j.neulet.2015.01.033

45. Yi H, Kim MA, Back SK, Eun JS, Na HS. A novel rat forelimb model of neuropathic pain produced by partial injury of the median and ulnar nerves. Eur J Pain. 2012;15(5):459-466.

46. Zhao W, Wang P, Song H, Sun N. Diosgenin attenuates neuropathic pain in a rat model of chronic constriction injury. Mol Med Rep. 2017;16(2):1559-1564. doi:10.3892/mmr.2017.6723

47. Campbell JN, Meyer RA. Mechanisms of neuropathic pain. Neuron. 2006;52(1):77-92. doi:10.1016/j.neuron.2006.09.021

48. Wu JJ, Lu YC, Hua XY, Ma SJ, Xu JG. A longitudinal mapping study on cortical plasticity of peripheral nerve injury treated by direct anastomosis and electroacupuncture in rats. World Neurosurg. 2018;114:e267-e282. doi:10.1016/j.wneu.2018.02.173

49. Melzack R. Evolution of the neuromatrix theory of pain. The Prithvi Raj Lecture: presented at the third World Congress of World Institute of Pain, Barcelona 2004. Pain Pract. 2010;5(2):85-94. doi:10.1111/ j.1533-2500.2005.05203.x

50. Yanagisawa T, Fukuma R, Seymour B, et al. Induced sensorimotor brain plasticity controls pain in phantom limb patients. Nat Commun. 2016;7:13209. doi:10.1038/ncomms 13209

51. Huo BB, Shen J, Hua XY, et al. Alteration of metabolic connectivity in a rat model of deafferentation pain: a 18F-FDG PET/CT study. J Neurosurg. 2019;1-9. doi:10.3171/2018.11.JNS181815

52. Peyron R. Functional brain imaging: what has it brought to our understanding of neuropathic pain? A special focus on allodynic pain mechanisms. Pain. 2016;157(Suppl 1):S67.

53. Peyron R, Faillenot I, Pomares FB, Bars DL, Garcia Larrea L, Laurent B. Mechanical allodynia in neuropathic pain. Where are the brain representations located? A positron emission tomography (PET) study. Eur J Pain. 2013;17(9):1327-1337. doi:10.1002/ j.1532-2149.2013.00307.x

54. Hanakawa T. Neural mechanisms underlying deafferentation pain: a hypothesis from a neuroimaging perspective. J Orthop Sci. 2012;17(3):331-335. doi:10.1007/s00776-012-0209-9

55. Garcia-Larrea L, Peyron R. Pain matrices and neuropathic pain matrices: a review. Pain. 2013;154(Suppl. 1):S29-S43. doi:10.1016/ j.pain.2013.09.001 


\section{Publish your work in this journal}

The Journal of Pain Research is an international, peer reviewed, open access, online journal that welcomes laboratory and clinical findings in the fields of pain research and the prevention and management of pain Original research, reviews, symposium reports, hypothesis formation and commentaries are all considered for publication. The manuscript management system is completely online and includes a very quick and fair peer-review system, which is all easy to use. Visit http:// www.dovepress.com/testimonials.php to read real quotes from published authors. 